\title{
Adaptive changes of pancreatic protease secretion to a short-term vegan diet: influence of reduced intake and modification of protein
}

\author{
Jaroslaw Walkowiak ${ }^{1,2}$, Edyta Mądry ${ }^{3 *}$, Aleksandra Lisowska ${ }^{1}$, Anna Szaflarska-Popławska ${ }^{4}$, \\ Marian Grzymisławski ${ }^{5}$, Hanna Stankowiak-Kulpa ${ }^{5}$ and Juliusz Przysławski ${ }^{6}$ \\ ${ }^{1} 1$ st Chair of Pediatrics, Department of Gastroenterology and Metabolism, Poznan University of Medical Sciences, \\ Poznan, Poland \\ ${ }^{2}$ Chair of Human Nutrition and Hygiene, Department of Dietetics, Poznan University of Life Sciences, Poznan, Poland \\ ${ }^{3}$ Department of Physiology, Poznan University of Medical Sciences, Swiecickiego 6, 60-572 Poznan, Poland \\ ${ }^{4}$ Department of Pediatrics, Allergology and Gastroenterology L. Rydygier Medical University, Bydgoszcz, Poland \\ ${ }^{5}$ Department of Gastroenterology and Human Nutrition, Poznan University of Medical Sciences, Poznan, Poland \\ ${ }^{6}$ Department of Human Nutrition, Poznan University of Medical Sciences, Poznan, Poland
}

(Received 12 November 2010 - Revised 26 April 2011 - Accepted 27 April 2011 - First published online 13 July 2011)

\section{Abstract}

In our previous study, we demonstrated that abstaining from meat, for 1 month, by healthy omnivores (lacto-ovovegetarian model) resulted in a statistical decrease in pancreatic secretion as measured by faecal elastase- 1 output. However, no correlation between relative and non-relative changes of energy and nutrient consumption and pancreatic secretion was documented. Therefore, in the present study, we aimed to assess the changes of exocrine pancreatic secretion with a more restrictive dietetic modification, by applying a vegan diet. A total of twenty-one healthy omnivores (sixteen females and five males) participated in the prospective study lasting for 6 weeks. The nutrient intake and faecal output of pancreatic enzymes (elastase-1, chymotrypsin and lipase) were assessed twice during the study. Each assessment period lasted for $7 \mathrm{~d}$ : the first before the transition to the vegan diet (omnivore diet) and the second during the last week of the study (vegan diet). The dietary modification resulted in a significant decrease in faecal elastase- $1(P<0 \cdot 05)$ and chymotrypsin output $(P<0 \cdot 04)$. The lipase excretion remained unchanged. The decrease in proteolytic enzymes was documented to be positively correlated with a decreased protein intake $(P<0 \cdot 05)$. In addition, elastase- 1 and chymotrypsin outputs were also related to the changes of protein type, plant $v$. animal ( $P<0.04$ and $P<0.03$, respectively). It was concluded that significant reduction and modification of protein intake due to a short-term vegan diet resulted in an adaptation of pancreatic protease secretion in healthy volunteers.

Key words: Exocrine pancreatic secretion: Elastase: Chymotrypsin: Vegan diet

The adaptation of pancreatic enzymes to the type of food available is one of the physiological advantages that allows animals to use nutrients and energy for metabolism as efficiently as possible. In today's era, numerous opportunities of genetic analysis exist, human genome mapping and even the sequencing of individual digestive enzyme DNA is possible, yet exocrine pancreatic adaptive mechanisms still remain unsolved. Direct research methodology for the collection of pancreatic juice is an invasive procedure and therefore, the challenge still remains to search for some non-invasive methods that would allow for the clarification of what exact exocrine pancreatic adaptive changes occur in humans.

Walkowiak et al. assessed the changes of exocrine pancreatic secretion in a group of healthy omnivores who modified their diet by abstaining from meat (following a lacto-ovovegetarian model) for 1 month $^{(1)}$. These dietary changes resulted in a statistically significant decrease in pancreatic secretion as measured by faecal elastase-1 (FE1) output. On the other hand, faecal chymotrypsin (FChT) and faecal lipase (FLp) excretions remained unchanged. Hypothetically, the major dietetic influence was related to the subject's exclusion of meat from their diet. The lack of elastin, the target molecule for elastase-1, might be responsible for the observed selective changes in its pancreatic secretion. However, no significant correlation between relative and non-relative changes of energy and nutrient consumption and pancreatic secretion has been documented. Therefore, in the present study, we aimed to assess the changes of exocrine pancreatic secretion with more restrictive dietetic modification, thus applying a vegan diet.

Abbreviations: FChT, faecal chymotrypsin; FE1, faecal elastase-1; FLp, faecal lipase.

*Corresponding author: E. Mądry, fax +48 61 8483362, email edytamadry@gmail.com 


\section{Materials and methods}

\section{Study design}

The study was performed in a prospective way and lasted for 6 weeks, 1 week of an omnivore diet followed by 5 weeks of a vegan diet. Once healthy omnivore volunteers started a vegan diet, they followed it for the period of the study. Nutrient intake was assessed twice during the length of the study. Each assessment period lasted for $7 \mathrm{~d}$ : the first before the transition to the vegan diet (omnivore diet); the second during the last week of the study (vegan diet). The faecal output of pancreatic enzymes: FE1, FChT and FLp was analysed during the same assessment periods ( $7 \mathrm{~d})$.

\section{Inclusion criteria}

The inclusion criteria were as follows: good general and nutritional status (normal $\mathrm{Hb}$ - females: $7.5-9.9 \mathrm{mmol} / \mathrm{l}$, males: 8.7-11.2 mmol/1; ferritin - females: 6.9-282.5 $\mathrm{g} / \mathrm{l}$, males: $18.7-323 \mu \mathrm{g} / \mathrm{l}$; albumin levels - 35.0-52.0 g/1); willingness to participate in the study.

\section{Exclusion criteria}

The exclusion criteria were as follows: any history of gastrointestinal or systemic diseases; any acute disease 1 month before or during the study; discontinuation of the vegan diet within the study period.

The sample size was established according Altman's normogram $^{(2)}$. Study volunteers were recruited from students and young workers of the Poznan University of Medical Sciences and there were no dropouts during the study. Only highly motivated and enthusiastic subjects were enrolled in the study. Finally, volunteers received detailed information on vegan products, as well as several examples of different well-balanced vegan meals. Each subject's diet compliance was checked three times per week of the study.

\section{Subjects}

A total of twenty-one healthy omnivores (sixteen females and five males) aged 21 to 35 years (mean 23.0 (SD 3.6) years) were included into the study. Their BMI values were in the range of $18 \cdot 0-29.9 \mathrm{~kg} / \mathrm{m}^{2}$ (mean 22.9 (SD 3.1)). Physical activity was assessed by a $7 \mathrm{~d}$ recall $^{(3)}$. All subjects were found to have moderate activity, which did not differ between the two periods of the study. Fat body mass assessed with the bioimpedance method (BIA-STA, Akern, Florence, Italy) was normal in all subjects, both before and after the dietary

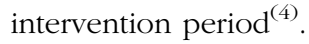

\section{Methods}

The assessment of nutrient intake (all available macro- and micronutrients) was based on the records of $7 \mathrm{~d}$ weighed rations. The dietetic records (with the use of scales with an approximation of $0 \cdot 1 \mathrm{~g}$ ) were collected by subjects at home. All subjects were given both oral and written instructions for data collecting, and they recorded all of their meals in a diary. The diet records were then reviewed and clarified with subjects (J. P.). The obtained data were analysed using our own, previously created, computer database (Microsoft Access 7.0; J. P.) prepared on the basis of tables for the composition assessment of the nutritional value of food products ${ }^{(5)}$. The degree to which the recommended intake was met was considered in relation to standard values given by the National Institute of Food and Nutrition in Warsaw ${ }^{(3)}$.

Faecal enzymes were determined in three independent samples of every stool. For further analysis, the mean value was taken. FE1 concentration (the test based on monoclonal antibodies) and FLp activity were measured using the immunoenzymatic method (ELISA), whereas FChT activity was measured using colorimetric method ${ }^{(6,7)}$. Faecal enzyme output was calculated according to the following formula:

$$
\mathrm{FEO}=\frac{\mathrm{FE}_{1} \times \mathrm{SW}_{1}+\cdots+\mathrm{FE}_{n} \times \mathrm{SW}_{n}}{3},
$$

where $\mathrm{FEO}$ is the faecal enzyme output, $\mathrm{FE}_{n}$ is the faecal enzyme concentration/activity in a subsequent $(n)$ stool and $\mathrm{SW}_{n}$ is the stool weight of a subsequent $(n)$ stool.

\section{Statistical analysis}

Statistical differences in nutrient intake and faecal enzyme output between two points of the assessment (paired data) were calculated with the use of the Wilcoxon-rank test. The relationship between the changes of faecal enzyme output and the changes in nutrients intake was assessed using multiple regression analysis.

If not stated otherwise, values are expressed as means and standard deviations. The levels of significance was set at $P<0.05$.

\section{Ethical considerations}

The study was conducted according to the guidelines laid down in the Declaration of Helsinki and all procedures involving human subjects were approved by the Ethical Committee of the Poznań University of Medical Sciences, Poland. Written informed consent was obtained from all subjects.

\section{Results}

A statistically significant decrease in FE1 $(P<0.05)$ and FChT output $(P<0 \cdot 04)$ was observed during the study. However, FLp excretion remained unchanged (Table 1). Comprehensive nutritional data are presented in Table 2. A significant reduction in body mass (63.7 (SD 10.2) v. 62.8 (SD 9.7) kg) and BMI (22.9 (SD 3.1) v. 22.6 (SD $2 \cdot 7) \mathrm{kg} / \mathrm{m}^{2}$ ) values was observed $(P<0 \cdot 001)$. Significant changes in the consumption of total, animal and plant proteins, fat, SFA and MUFA $(P<0.0001$ for all), dietary fibres $(P<0 \cdot 0001)$, Se $(P<0.005)$, as well as for energy $(P<0.003)$ and carbohydrate $(P<0.0006)$ intake were documented. However, PUFA consumption did not change. Additionally, with the lowering of protein and fat intake, 
Table 1. Daily faecal elastase-1 (FE1), chymotrypsin (FChT) and lipase (FLp) outputs on an omnivore and vegan diet (Medians and quartiles)

\begin{tabular}{lcccccc}
\hline & \multicolumn{2}{c}{ Omnivore diet } & & \multicolumn{2}{c}{ Vegan diet } & \\
\cline { 2 - 3 } Enzyme & Median & 1st-3rd quartile & & Median & 1st-3rd quartile & $P$ \\
\hline FE1 $(\mu \mathrm{g} / \mathrm{g})$ & 71543 & $39554-89300$ & & 44576 & $27808-74560$ & 0.05 \\
FChT $(\mathrm{U} / \mathrm{g})$ & 1602 & $1328-2698$ & & 1037 & $966-1958$ & 0.04 \\
FLp $(\mathrm{U} / \mathrm{g})$ & 8275 & $4460-14549$ & & 7998 & $4323-13427$ & NS \\
\hline
\end{tabular}

a significant decrease $(P<0.001$ for both) in the percentage of energy consumed as protein (15.3 (SD 2.4) v. 11.8 (SD 1.7)\%) and fat $(32 \cdot 0(\mathrm{SD} 4 \cdot 2) v \cdot 15 \cdot 0(\mathrm{SD} 2 \cdot 2) \%)$ was observed.

No statistically significant correlations between relative and non-relative changes of energy, carbohydrate and fat (including SFA, MUFA and PUFA) consumption and faecal output of pancreatic enzymes were documented. However, the decrease in proteolytic enzymes was documented to be positively correlated with the decrease in protein intake $(P<0.05)$. In addition, FE1 and FChT outputs were also related to the changes in protein type (plant $v$. animal; $P<0.04$ and $P<0 \cdot 03$, respectively).

\section{Discussion}

Although the statement 'exocrine pancreatic function can be modified by the composition of the diet' seems to be obvious since Ivan Pavlov's time, the detailed mechanisms of this phenomenon still remain unclear in humans. To date, much of our understanding of digestive enzymes comes from animal studies. Relatively little information is available in humans, which seems understandable given the invasiveness of the typical testing procedures. Since differences among species have been demonstrated between the adaptability of pancreatic enzymes ${ }^{(7)}$, the search for a non-invasive method that will allow for a full understanding of human exocrine pancreatic adaptive changes still remains an important, unresolved issue. The indirect methods of digestive pancreatic enzyme assessment combined with the elimination diet that we proposed might be the useful tool for further examinations of exocrine pancreatic adaptive mechanisms in human subjects. However, the measurement of faecal enzymes as a marker of pancreatic enzyme secretion has some limitations ${ }^{(8,9)}$.

Veganism, one of the most restrictive types of vegetarianism, may create an interesting opportunity that might be able to contribute to answering certain questions in this field. A vegan diet consists of consuming only vegetables, fruits, grains and nuts without the addition of milk products and eggs and with the exclusion of all forms of flesh (meat, fowl and seafood). The study based on the vegetarian model seems to be justified not only by the cognitive but also by the practical point of view. For example, a plant-based diet can provide a useful dietary management for renal patients, giving them more chances for long-lasting dietary compliance $^{(10)}$ or such a diet may also have important beneficial effects on diabetic nephropathy, eliminating the need for restricted total protein intake ${ }^{(11)}$.

In the present study, the use of the prospective vegan model revealed a selective adaptation of pancreatic secretion. The decrease in proteolytic enzyme outputs was documented to be positively correlated with the decrease in protein intake. Although volunteers consumed less fat, FLp excretion remained unchanged. Zoppi et al. documented in premature infants that high-protein diets resulted in increased levels of trypsin and lipase ${ }^{(12)}$. In another study of premature infants, the significant increase in trypsin and lipase output in a subgroup fed with high-protein soya-based formula has been documented $^{(13)}$. In our previous study with opposite dietary modifications (decreased protein) in healthy adult volunteers, concordant regulatory mechanisms were observed between

Table 2. Changes in daily energy and nutrient intake resulting from the diet modification (omnivore $v$. vegan diet)

(Mean values, standard deviations, medians and quartiles)

\begin{tabular}{|c|c|c|c|c|c|c|c|c|c|c|}
\hline \multirow[b]{2}{*}{ Nutrient } & \multicolumn{3}{|c|}{ Omnivore diet } & \multicolumn{3}{|c|}{ Vegan diet } & \multicolumn{3}{|c|}{ Relative changes* } & \multirow[b]{2}{*}{$P$} \\
\hline & Mean & Median & 1st-3rd quartile & Mean & Median & 1st-3rd quartile & Mean & SD & Median & \\
\hline Energy (kJ) & $9213 \cdot 17$ & 9070.91 & $8096 \cdot 04-9865 \cdot 87$ & 8016.54 & 8321.98 & $7539.57-8953.76$ & 364.01 & 92.05 & 383.67 & 0.03 \\
\hline Protein $(\mathrm{g})$ & 84.3 & 83.5 & $72.4-90.5$ & $56 \cdot 7$ & 55.8 & $50.1-59.9$ & $67 \cdot 3$ & 21.5 & $66 \cdot 8$ & 0.0001 \\
\hline Animal protein (g) & $52 \cdot 4$ & $53 \cdot 1$ & $43 \cdot 7-62 \cdot 2$ & 0.0 & 0.0 & $0.0-0.0$ & 0.0 & 0.0 & 0.0 & 0.0001 \\
\hline Plant protein $(\mathrm{g})$ & 31.9 & 30.4 & $21.3-39.8$ & $56 \cdot 7$ & $55 \cdot 8$ & $50.1-59.9$ & $177 \cdot 7$ & $43 \cdot 1$ & $183 \cdot 6$ & 0.0001 \\
\hline Carbohydrates (g) & 281.0 & 283.4 & $245 \cdot 2-321 \cdot 8$ & 352.8 & 369.0 & $324.5-399.7$ & $125 \cdot 6$ & $29 \cdot 8$ & $130 \cdot 2$ & 0.0006 \\
\hline Fat $(\mathrm{g})$ & $82 \cdot 3$ & $77 \cdot 8$ & $69 \cdot 8-85 \cdot 1$ & 30.9 & $32 \cdot 2$ & $29.1-35.4$ & 37.5 & $20 \cdot 2$ & 41.4 & 0.0001 \\
\hline SFA $(\mathrm{g})$ & 28.9 & $27 \cdot 1$ & $24.9-30.2$ & $6 \cdot 6$ & $6 \cdot 9$ & $6.2-7.9$ & $22 \cdot 8$ & $13 \cdot 3$ & $25 \cdot 5$ & 0.0001 \\
\hline MUFA (g) & 31.4 & 29.7 & $25.2-33.8$ & $10 \cdot 4$ & $10 \cdot 9$ & $9.8-11.8$ & 33.1 & 33.1 & $36 \cdot 7$ & 0.0001 \\
\hline PUFA (g) & $13 \cdot 8$ & $13 \cdot 2$ & $10 \cdot 9-16 \cdot 1$ & $10 \cdot 8$ & $11 \cdot 2$ & $10 \cdot 0-12 \cdot 3$ & $78 \cdot 3$ & $40 \cdot 3$ & 84.8 & NS \\
\hline Fibre $(\mathrm{g})$ & $18 \cdot 2$ & $18 \cdot 8$ & $15 \cdot 3-22 \cdot 1$ & 43.2 & $42 \cdot 9$ & $37.9-46.5$ & 237.4 & $23 \cdot 8$ & $228 \cdot 2$ & 0.0001 \\
\hline $\mathrm{Se}(\mu \mathrm{g})$ & $38 \cdot 2$ & 39.9 & $30 \cdot 1-47 \cdot 2$ & $24 \cdot 3$ & 24.9 & $22 \cdot 6-26 \cdot 8$ & 63.6 & $25 \cdot 2$ & $62 \cdot 4$ & 0.005 \\
\hline
\end{tabular}

* Values are expressed as a percentage of the original value. 
protein intake and protease secretion (both were decreased). On the contrary though, in the present study, no changes of lipolytic activity were observed. However, it has been documented earlier that qualitative changes in a dietary fat (SFA, MUFA and PUFA) profile could still play a role in pancreatic enzyme secretions ${ }^{(14,15)}$. According to Saraux et al., in rats, lipase adapts quantitatively to the amount of its respective substrates in the diet by an increase in its specific activity and total contents. The length of the fatty acid chain has been shown to influence the pancreatic lipase level, whereas the degree of unsaturation appears to have no effect on the lipase level in this organ ${ }^{(16)}$. In dogs, however, lipase output was significantly lower in the group fed with the diet rich in MUFA (compared with PUFA) ${ }^{(17)}$. Pancreatic lipase activity in rats that were fed diets with 11, 40, 47, 54, 67 and $75 \% \mathrm{~kJ}$ as fat was not significantly different when the dietary fats were less than $47 \% \mathrm{~kJ}$. It was though maximally stimulated when the dietary fat content was 54 and $67 \% \mathrm{~kJ}^{(18)}$. These findings suggest that pancreatic lipase may adapt primarily to the amount of dietary fat and may respond to the type of fat only below certain threshold levels, as was observed in the study quoted above. Few reports in the literature to date have considered a diet with a reduced fat content (as we have done in the present study). The effect of ingesting isoenergetic and isonitrogenous diets with different amounts of lipid $(0-30 \%)$ on the exocrine pancreas was studied by Wicker \& Puigserver. Lipid-free diets and diets containing $1 \%$ lipid were found to have little effect on pancreatic proteins compared with lipid-rich diets ${ }^{(19)}$.

The changes in nutrient intake in the present study are more complex than in simple experiments, which complicates the analysis of the data. However, we observed that FLp excretion remained unchanged despite the decrease in fat intake in our subjects. It is possible, that the decrease in lipase production associated with low fat intake could be halted by the high dietary fibre content clearly connected with a vegetarian diet, and documented in the present study. Dukehart et $a l^{(20)}$ has demonstrated that in human subjects, 4 weeks of a fibre-rich diet resulted in significant increases in pancreatic lipase concentrations. Therefore, unchanged lipase output may be related to the balance between factors that stimulate and inhibit its secretion.

Relationships between FE1 and FChT stool concentrations and changes in animal/plant protein consumption were also documented in the present study. The observed reduction of faecal output of pancreatic enzymes remains in concordance with previous observations from a lacto-ovovegetarian model $^{(1)}$. It may, however, also be suggested that the change in the type of proteins (animal $v$. plant) may play a role in an adaptive decrease in FE1 secretion. The reduction of FE1 output $(31.7 v .37 \cdot 7 \%)$ in both publications is not different. However, protein consumption is significantly more reduced due to the vegan diet compared with the previous lactoovovegetarian model $(93.5 \mathrm{v} .67 \cdot 3 \%)$.

Elastase is one of the serine endopeptidases found in pancreatic juice. The designation of an enzyme as an elastase depends on its ability to digest elastin, a fibrillar protein of connective tissue found in meat. Elastin is composed of $90 \%$ of the five amino acids, leucine, isoleucine, glycine, proline and valine, and it also contains multiple lysine-derived cross-links. Chymotrypsin, the other pancreatic endopeptidase of the serine protease family, hydrolyses peptides with aromatic amino acids in their structure (phenylalanine, tyrosine and tryptophan) ${ }^{(19)}$. Animal and plant proteins differ in their contents of particular amino acids ${ }^{(20)}$. The elimination of meat from the diet results in the lack of elastin, the target molecule for elastase-1, and this may be what is responsible for the observed decrease in its pancreatic secretion. However, exclusion of dairy products and eggs (high content of aromatic amino acids) could affect the lowering of chymotrypsin concentrations as documented in the present study, especially since 5 weeks of the lacto-ovovegetarian diet did not result in chymotrypsin decline ${ }^{(1)}$.

Pancreatic serine proteases are synthesised as inactive pro-enzymes and are all (also trypsin by itself) activated by trypsin ${ }^{(21-23)}$. Hence, it can be assumed the trypsin inhibitors could potentially influence the activation of other enzymes including elastase-1 and chymotrypsin. A soyabean trypsin inhibitor has been shown to decrease the activity of trypsin in rats ${ }^{(24)}$. However, the effect on human trypsin does not appear to be a potential hazard in human subjects, thus soya is commonly added to products commercially available for omnivores ${ }^{(25)}$. However, the hypothetical influence of soya products cannot be possibly assessed with the data provided in the present study.

Other factors possibly influencing pancreatic secretion in vegans (documented in the present study) are low Se intake $^{(26)}$ and a high fibre content in the diet ${ }^{(27,28)}$. Nutritionally induced pancreatic atrophy was demonstrated in Se-deficient chicks $^{(29,30)}$ but a similar phenomenon has never been suggested in other species, including human subjects. In vitro studies have demonstrated that dietary fibre, as well as its components, have varying inhibitory effects on pancreatic trypsin, amylase and lipase activities. These inhibitory effects are caused by dietary fibre-induced alterations in viscosity, $\mathrm{pH}$ and the non-specific binding of these pancreatic enzymes ${ }^{(20,27,28)}$. In contrast to in vitro studies, in vivo studies on animals (rats) that were fed dietary fibres for 2-6 weeks have demonstrated an increase in pancreatic enzyme secretions $^{(31,32)}$. In human subjects, during a 4-week dietary fibre supplementation programme, no changes were observed in trypsin concentration and output, while a marked increase in lipase concentration has been reported, as mentioned earlier ${ }^{(20)}$

In conclusion, a significant reduction and modification of protein intake due to a short-term vegan diet resulted in an adaptation of pancreatic protease secretion in healthy volunteers. The nutritional changes documented in the recent study are very complex. This makes it difficult to interpret and draw conclusions from the collected data.

\section{Acknowledgements}

The study was supported by the Polish Scientific Research Committee (3 P05D 033 22). There are no conflicts of interest. The authors' contributions are as follows: J. W. and J. P. designed the study. J. W., A. L. and J. P. collected the data. 
E. M. and J. W. wrote the draft of the manuscript. All authors are responsible for search of the literature, analysis and interpretation of the data, drafting and/or revising of the manuscript.

\section{References}

1. Walkowiak J, Wądołowska L, Szaflarska-Popławska A, et al. (2007) The elimination of meat from the diet selectively decreases pancreatic elastase secretion. Br J Nutr 98 , $154-158$

2. Petrie A \& Sabin C (2005) Sample size calculation. In Medical Statistics at a Glance, pp. 84-86. Oxford: Blackwell Publishing Ltd.

3. Ziemlański S \& Bułak-Jachymczyk B (2001) Energy needs in humans. In Normal Values in Human Nutrition. Physiological Basis, pp. 35-57 [S Ziemlański, editor]. Warsaw: PZWL (in Polish).

4. Jaffrin M (2009) Body composition determination by bioimpedance: an update. Curr Opin Clin Nutr Metab Care 12, $482-486$.

5. Kunachowicz H, Nadolna I, Przygoda B, et al. (2005) Nutritional value of food products, pp. 1-671. Warsaw: Instytut Żywienia i Żywności (in Polish).

6. Walkowiak J, Herzig KH, Strzykala K, et al. (2002) Fecal elastase- 1 is superior to fecal chymotrypsin in the assessment of pancreatic involvement in cystic fibrosis. Pediatrics 110, E7.

7. Walkowiak J, Lisowska A, Przysławski J, et al. (2004a) Faecal elastase test is superior to faecal lipase test in the assessment of exocrine pancreatic function in cystic fibrosis. Acta Paediatr 93, 1042-1045.

8. Walkowiak J, Nousia-Arvanitakis S, Henker J, et al. (2005) Indirect pancreatic function tests in children. J Pediatr Gastroenterol Nutr 40, 107-114.

9. Behrman HR \& Kare MR (1969) Adaptation of canine pancreatic enzymes to diet composition. J Physio 205, 667-676

10. Cupisti A, Morelli E, Meola M, et al. (2002) Vegetarian diet alternated with conventional low-protein diet for patients with chronic renal failure. J Ren Nutr 12, 32-37.

11. Jibani MM, Bloodworth LL, Foden E, et al. (1991) Predominantly vegetarian diet in patients with incipient and early clinical diabetic nephropathy: effects on albumin excretion rate and nutritional status. Diabet Med 8, 949-953.

12. Zoppi G, Andreotti G, Pajno-Ferrara F, et al. (1972) Exocrine pancreas function in premature and full term neonates. Pediatr Res 6, 880-886.

13. Lebenthal E, Choi TS \& Lee PC (1981) The development of pancreatic function in premature infants after milk-based and soy-based formulas. Pediatr Res 15, 1240-1244.

14. Egberts J, Brunke G, Kiehne K, et al. (2000) CCK release by long-chain unsaturated fatty acids from isolated perfused mucosal cells. Gastroenterology 118, A301.

15. Alarcon de la Lastra C, Barranco MD, Motilva V, et al. (2001) Mediterranean diet and health: biological importance of olive oil. Curr Pharm Des 7, 933-950.
16. Saraux B, Girard-Globa A, Ouagued M, et al. (1982) Response of the exocrine pancreas to quantitative and qualitative variations in dietary lipids. Am J Physiol $\mathbf{2 4 3}$, G10-G15.

17. Ballesta MC, Mañas M, Mataix FJ, et al. (1990) Long-term adaptation of pancreatic response by dogs to dietary fats of different degrees of saturation: olive and sunflower oil. Br J Nutr 64, 487-496.

18. Sabb JE, Godfrey PM \& Brannon PM (1986) Adaptive response of rat pancreatic lipase to dietary fat: effects of amount and type of fat. J Nutr 116, 892-899.

19. Wicker C \& Puigserver A (1987) Effects of inverse changes in dietary lipid and carbohydrate on the synthesis of some pancreatic secretory proteins. Eur J Biochem 162, 25-30.

20. Dukehart MR, Dutta SK \& Vaeth J (1989) Dietary fiber supplementation: effect on exocrine pancreatic secretion in man. Am J Clin Nutr 50, 1023-1028.

21. Whitcomb DC \& Lowe ME (2007) Human pancreatic digestive enzymes. Dig Dis Sc 52, 1-17.

22. Gawecki J (1997) Proteins in food and nutrition, pp. 1-107. Poznan, Poland: August Cieszkowski Agricultural University (in Polish).

23. Hubbard SJ, Eisenmenger F \& Thornton JM (1994) Modeling studies of the change in conformation required for cleavage of limited proteolytic sites. Protein Sci 3, 757-768.

24. Fölsch UR \& Creutzfeldt W (1985) Adaptation of the pancreas during treatment with enzyme inhibitors in rats and man. Scand J Gastroenterol Suppl 112, S54-S63.

25. Flavin DF (1982) The effects of soybean trypsin inhibitors on the pancreas of animals and man: a review. Vet Hum Toxicol 24, 25-28.

26. Jackson MJ, Broome CS \& Mc Ardle F (2003) Marginal dietary selenium intakes in the UK: are there functional consequences? J Nutr 133, Suppl. 1, 1557S-1559S.

27. Isaksson G, Lundquist I \& Ihse I (1982) Effect of dietary fiber on pancreatic enzyme activity in vitro. Gastroenterol 82, 918-924.

28. Dutta SK \& Hlasko J (1985) Dietary fiber in pancreatic disease: effect of high fiber diet on fat malabsorption in pancreatic insufficiency and in vitro study of the interaction of dietary fiber with pancreatic enzymes. Am J Clin Nutr $\mathbf{4 1}$, $517-525$.

29. Noguchi T, Langevin ML, Combs GF, et al. (1973) Biochemical and histochemical studies of the selenium-deficient pancreas in chicks. J Nutr 103, 444-453.

30. Combs GF Jr, Liu CH, Lu ZH, et al. (1984) Uncomplicated selenium deficiency produced in chicks fed a corn-soy-based diet. J Nutr 114, 964-976.

31. Isaksson G, Lilja P, Lundquist I, et al. (1983) Influence of dietary fiber on exocrine pancreatic function in the rat. Digestion 27, 57-62.

32. Sommer H \& Kasper H (1984) Effect of long-term administration of dietary fiber on the exocrine pancreas in the rat. Hepatogastroenterology 31, 176-179. 